\title{
IMPLEMENTASI DATA PANEL SPASIAL TERHADAP TINGKAT PRODUK DOMESTIK REGIONAL BRUTO DI PROVINSI BALI
}

\author{
Ni Made Ary Dharma Widya Astuti ${ }^{\S}$, Made Susilawati ${ }^{2}$, Ni Luh Putu Suciptawati ${ }^{3}$ \\ ${ }^{1}$ Program Studi Matematika, Fakultas MIPA - Universitas Udayana [Email: darmaary40@gmail.com] \\ ${ }^{2}$ Program Studi Matematika, Fakultas MIPA - Universitas Udayana [Email: mdsusilawati@unud.ac.id] \\ ${ }^{3}$ Program Studi Matematika, Fakultas MIPA - Universitas Udayana [Email: suciptawati@unud.ac.id] \\ ${ }^{\S}$ Corresponding Author
}

\begin{abstract}
Gross Regional Domestic Product (GRDP) is an economic indicator to see the economic movements of a region during a certain period, whether based on current and constant price. Economic activities in a region use the GRDP calculation based on current prices by industrial base year 2010. In 2019, Bali's economic growth increased by 5.63\%, exceeding national economic growth of $5.02 \%$. Using spatial panel data in analysis consists of common effect model, fixed individual effect model, fixed time effect model, random effect model, and spatial lag fixed effect model. The best model to modeling GRDP Bali Province is spatial lag fixed effect which has a difference in constant values at any time, with $R^{2}$ of 99.41 percent, the remaining is explained by other variables not examined
\end{abstract}

Keywords: GDRP, Bali Province, Spatial panel data

\section{PENDAHULUAN}

Keberhasilan pembangunan pada suatu wilayah dilihat berdasarkan tingkat pertumbuhan ekonominya. Pertumbuhan ekonomi memiliki peran yang penting terhadap kemajuan suatu wilayah, sehingga kondisi perekonomian diharapkan terus membaik dari tahun ke tahun (BPS Provinsi Bali, 2019). Laju pertumbuhan ekonomi dilihat dari indikator ekonomi yaitu indikator ekonomi regional atau produk domestik regional bruto (PDRB). Pada indikator itu akan menampilkan informasi mengenai pergerakan ekonomi yang di hasilkan suatu wilayah.

PDRB ialah banyaknya total nilai tambah produk serta jasa akhir diperoleh setiap seluruh usaha dalam suatu wilayah (Bank Indonesia, 2019). PDRB mempunyai dua ketegori seperti PDRB atas dasar berlaku yang dipakai untuk struktur ekonomi di suatu daerah. Terdapat juga PDRB atas dasar harga konstan dipakai melihat pergerakan laju ekonomi secara menyeluruh pada setiap tahunnya (BPS Bali, 2019). Kegiatanan perekonomian di suatu wilayah menggunakan perhitungan atas dasar harga berlaku, sehingga mengetahui prioritas dari jenis-jenis lapangan usaha di suatu daerah.
Tahun dasar PDRB terjadi perubahan sebanyak enam kali mulai dari tahun dasar 1960;1973;1983;1993;2000; dan terakhir tahun 2010. Selain mengalami perubahan tahun dasar, PDRB juga mengalami perkembangan kategori sektor yang semula sembilan kategori menjadi 17 kategori sektor menurut lapangan usaha. Perkembangan pertumbuhan ekonomi Bali setiap tahunnya mengalami peningkatan. Pada tahun 2019 pertumbuhan ekonomi Bali meningkat sebesar $5,63 \%$ melebihi pertumbuhan ekonomi nasional yang hanya sebesar 5,02\% (BPS Provinsi Bali, 2019). Berdasarkan PDRB atas dasar harga berlaku tahun 2019 Kabupaten Badung memiliki PDRB tertinggi sebesar 62.794,84 miliar rupiah dibandingkan Kabupaten Bangli hanya sebesar 6.999,41 miliar rupiah.

Penelitian Haryanto \& Saryono (2018) merupakan penelitian menggunakan PDRB di sektor konstruksi Jawa Timur. Kesimpulan pada penelitian tersebut diperoleh faktor-faktor yang berpengaruh signifikan terhadap PDRB sektor konstruksi yaitu pendapatan asli daerah dan indeks pembangunan manusia. Penelitian yang dilakukan oleh Widiadnyani et al (2019) menggunakan pendekatan regresi data panel 
untuk memodelkan angka partisipasi sekolah jenjang SMA sederajat di Bali. Hasil dari penelitian tersebut diperoleh model terbaik yaitu fixed individual effect dengan $R^{2}=$ $61,49 \%$. Penelitian memakai data panel spasial, salah satunya dilakukan oleh Lasdiyanti et al (2019) untuk memodelkan human development index with spatial panel data. Hasil dari penelitian tersebut memperoleh model spatial error fixed effect dengan $R^{2}=99,99 \%$.

Data panel gabungan terdahap data cross section dan juga data time series (Gujarati \& Porter, 2009). Gabungan tersebut akan menghasilkan tingginya varianbilitas, dan juga besarnya degree of freedom (Baltagi, 2005). Model data panel memiliki beberapa pendekatan seperti model common effect yang menjadi pendekatan sederhana, karena tidak memperhatikan perbedaan unit cross section dan juga unit time series. Terdapat juga model fixed effect yang estimasinya memakai penambah dummy variabel untuk melihat beda intersep, sedangkan model random effect mengatasi kelemahan fixed effect model dengan penambahan variabel error terms pada model data panel.

Regresi data panel dapat dikembangkan dengan melibatkan efek ruang atau bisa dikenal sebagai model regresi data panel spasial. Matriks pembobot pada regresi spasial menjadi hal utama dalam pemodelan, yang digunakan untuk menggambarkan hubungan antar wilayah yang berdekatan. Efek spasial sering terjadi antara suatu wilayah dengan wilayah lain yang saling bertetanggan, agar mengetahui adanya efek spasial dilakukan dengan dependensi spasial yang terdiri dari model spatial lag yang memiliki kebergantungan pada variabel respon, dan model spatial error memiliki kebergantungan terhadap galat antarlokasi.

Adanya pengamatan pada unit cross section yang serupa serta menambahkan unsur kedudukan akan memungkinkan terjadi kebergantungan terhadap pengamatan, sehingga terjadi kemungkinan amatan suatu kedudukan dipengaruhi oleh kedudukan yang menjadi tetangganya. Penelitian ini bertujuan untuk mengetahui model PDRB Provinsi Bali dengan mengunakan metode data panel spasial dan sektor-sektor lapangan usaha apa saja yang menjadi prioritas terhadap PDRB Bali.

\section{METODE PENELITIAN}

\subsection{Jenis dan Sumber Data}

Menggunakan data sekunder, dengan amatan yang diteliti berupa PDRB berdasarkan atas dasar harga berlaku menurut lapangan usaha. Diperoleh sumber dari Badan Pusat Statistik berupa data tahun dari tahun 2010 sampai tahun 2019 di masing-masing kabupaten/kota Provinsi Bali.

\subsection{Variabel Penelitian}

Variabel respon berupa data PDRB berdasarkan atas dasar harga berlaku, sedangkan variabel bebas menggunakan sektorsektor menurut lapangan usaha diambil di Badan Pusat Statistik dengan sektor pertambangan tidak dilibatkan karena tidak memiliki nilai.

\subsection{Metode Analisis Data}

Tahapan pertama sebelum memodelkan PDRB Provinsi Bali yaitu, pada penelitian ini variabel penelitian sebanyak 17 variabel sesuai dengan kategori sektor PDRB menurut lapangan usaha, sehingga variabel penelitian lebih banyak dibandingkan jumlah cross section yang hanya terdiri atas 9 kabupaten/kota di Bali. Untuk melakukan analisis, model random effect mengharuskan jumlah unit cross section harus melebihi jumlah variabel penelitian oleh karena itu, dilakukan penghilangan variabel yang memiliki korelasi tinggi karena sudah dapat diwakilkan oleh variabel lainnya sehingga pengaruhnya akan sama. Tahapan selanjutnya, dalam memodelkan sebagai berikut:

1. Melakukan estimasi model yaitu model common effect (CEM), model fixed effect (FEM), dan model random effect (REM).

a. Model common effect

Model ini mengasumsikan koefisien slope dan intersep konstan antar individu dan waktu. Menggunakan metode ordinanary least squares untuk melakukan estimasi parameter (Baltagi, 2005). Bentuk persamaan model adalah:

$$
\begin{aligned}
& Y_{i t}=\alpha+\sum_{k=1}^{K} \beta_{k} X_{k i t}+u_{i t} \\
& i=1,2, \cdots, N ; t=2010,2011, \cdots, T
\end{aligned}
$$


b. Model fixed effect

Model tersebut mengasumsi untuk koefisien slope konstan antar individu dan juga waktu, namun intersep berbeda antar individu (Gujarati \& Porter, 2009). Perbedaan intersep mengakibatkan adanya penambahan dummy variabel pada model. Model fixed effect membentuk dua model yaitu model fixed individual effect yang dummy variabelnya terdiri atas sembilan kabupaten/kota, dengan bentuk persamaan model adalah:

$Y_{i t}=\sum_{j=1}^{N} D_{j t} \alpha_{j}+\sum_{k=1}^{K} \beta_{k} X_{k i t}+u_{i t}$

$j=1,2, \cdots, N ; t=2010, \cdots, T$

dengan $D_{j t}$ bernilai 1 jika $j=i$

Sedangkan model fixed time effect dummy variabelnya terdiri atas tahun 2010; 2011; 2012; 2013; 2014; 2015; 2016; 2017; 2018; dan 2019. Bentuk persamaan model adalah:

$$
\begin{aligned}
& Y_{i t}=\sum_{s=1}^{N} D_{i s} \alpha_{s}+\sum_{k=1}^{K} \beta_{k} X_{k i t}+u_{i t} \\
& ; s=1,2, \cdots, N ; t=2010,2011, \cdots, T \\
& \text { dengan } D_{i s} \text { bernilai } 1 \text { jika } s=t
\end{aligned}
$$

c. Model random effect

Model ini untuk menangani permasalahan pada FEM. Penambahan dummy variabel pada model fixed effect akan menghalangi model aslinya, sehingga terdapat penambahan variabel error term pada model. Bentuk persamaan model adalah:

$Y_{i t}=\alpha_{i}+\sum_{k=1}^{K} \beta_{k} X_{k i t}+w_{i t}$

$i=1,2, \cdots, N ; t=2010, \cdots, T$

dengan $w_{i t}$ merupakan gabungan galat yaitu $u_{i t}+\varepsilon_{i}$

2. Melakukan pemilihan model data panel menggunakan uji Chow untuk melihat keberadaan intersep, dan juga melakukan pemilihan model regresi data panel menggunakan uji Hausman.

3. Melakukan pengujian signifikan parameter dengan menggunakan uji F (simultan) dan uji t (parsial).

4. Menetapkan matriks pembobot, yang pada penelitian ini menggunakan metode queen contiguity dengan bentuk matriks sebagai berikut (LeSage, 1999):

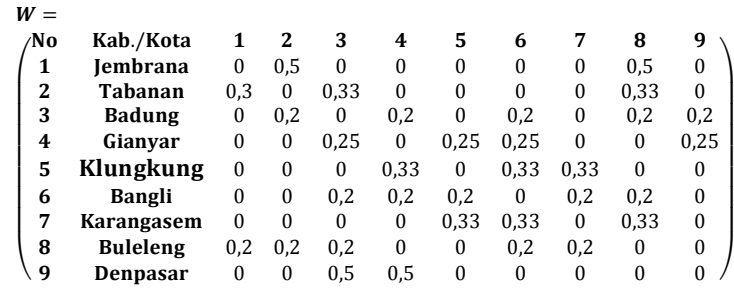

5. Melakukan uji kebergantungan spasial untuk mengetahui adanya pengaruh spasial.

6. Melakukan penduga parameter terhadap model spasial yang terpilih.

7. Melakukan interpretasi terhadap model hasil akhir.

\section{HASIL DAN PEMBAHASAN}

\subsection{Model Common Effect}

Nilai estimasi model common effect

\begin{tabular}{|c|c|c|c|c|}
\hline Variabel & $\begin{array}{l}\text { Para } \\
\text { meter }\end{array}$ & $\begin{array}{l}\text { Nilai } \\
\text { Estimasi }\end{array}$ & $t_{\text {hit }}$ & $p$-Value \\
\hline Intersep & $\alpha$ & $-1,043 \mathrm{e}+03$ & $-2,845$ & 0,005 \\
\hline $\begin{array}{l}\text { Pertanian, } \\
\text { kehutanan, dan } \\
\text { perikanan } \\
\text { (PKP) }\end{array}$ & $\beta_{1}$ & $2,018 \mathrm{e}+00$ & 13,692 & $<2,2 \mathrm{e}-16$ \\
\hline $\begin{array}{l}\text { Industri } \\
\text { pengolahan (IP) }\end{array}$ & $\beta_{2}$ & $1,972 \mathrm{e}+00$ & 3,709 & 0,000 \\
\hline $\begin{array}{l}\text { Pengadaan } \\
\text { listrik dan gas } \\
\text { (PLG) }\end{array}$ & $\beta_{3}$ & $5,5327 e+01$ & 4,854 & $5,687 \mathrm{e}-06$ \\
\hline $\begin{array}{l}\text { Konstruksi } \\
\text { (KTK) }\end{array}$ & $\beta_{5}$ & $4,1432 \mathrm{e}+00$ & 9,095 & $4,645 \mathrm{e}-14$ \\
\hline $\begin{array}{l}\text { Transportasi } \\
\text { dan } \\
\text { pergudangan } \\
\text { (TP) }\end{array}$ & $\beta_{7}$ & $1,3081 e+00$ & 16,778 & $<2,2 \mathrm{e}-16$ \\
\hline $\begin{array}{l}\text { Jasa Perusahaan } \\
\text { (JPRS) }\end{array}$ & $\beta_{12}$ & $6,8105 \mathrm{e}-01$ & 0,192 & 0,848 \\
\hline \multirow[t]{4}{*}{$\begin{array}{l}\text { Jasa Pendidikan } \\
\text { (JP) }\end{array}$} & $\beta_{14}$ & $2,5021 \mathrm{e}-01$ & 0,580 & 0,563 \\
\hline & & & $F_{\text {hit }}$ & 1447,52 \\
\hline & & & $p_{\text {value }}$ & $\begin{array}{l}<2,22 \mathrm{e} \\
-16\end{array}$ \\
\hline & & & $R^{2}$ & $99,19 \%$ \\
\hline
\end{tabular}
dimaksud pada Tabel 1.

Tabel 1. Parameter Model Common Effect

Sumber: Data diolah, 2020

\subsection{Model Fixed Effect}

Nilai estimasi model fixed individual effect dan fixed time effect ditunjukkan di Tabel 2. serta Tabel 3. 
Tabel 2. Parameter Model Fixed Individual Effect

\begin{tabular}{|c|c|c|c|c|}
\hline Variabel & $\begin{array}{l}\text { Para } \\
\text { meter }\end{array}$ & $\begin{array}{c}\text { Nilai } \\
\text { Estimasi }\end{array}$ & $t_{\text {hit }}$ & $p$-Value \\
\hline Jembrana & $\alpha_{1}$ & $-1492,76$ & $-2,41 !$ & 0,017 \\
\hline Tabanan & $\alpha_{2}$ & $-1103,20$ & $-0,99 \varepsilon$ & 0,321 \\
\hline Badung & $\alpha_{3}$ & 2743,34 & 2,862 & 0,005 \\
\hline Gianyar & $\alpha_{4}$ & $-2334,48$ & $-1,79$ ! & 0,076 \\
\hline Klungkung & $\alpha_{5}$ & $-1003,87$ & $-2,09 t$ & 0,039 \\
\hline Bangli & $\alpha_{6}$ & $-1427,70$ & $-2,57$ & 0,012 \\
\hline Karangasem & $\alpha_{7}$ & $-286,71$ & $-0,31$ & 0,756 \\
\hline Buleleng & $\alpha_{8}$ & 146,06 & 0,122 & 0,902 \\
\hline Denpasar & $\alpha_{9}$ & $-893,47$ & $-0,51 \varepsilon$ & 0,605 \\
\hline $\begin{array}{l}\text { Pertanian, } \\
\text { kehutanan, dan } \\
\text { perikanan (PKP) }\end{array}$ & $\beta_{1}$ & 1,953 & 6,049 & $\begin{array}{r}5,464 \mathrm{e}- \\
08\end{array}$ \\
\hline $\begin{array}{l}\text { Industri } \\
\text { pengolahan (IP) }\end{array}$ & $\beta_{2}$ & 2,982 & 2,326 & 0,022 \\
\hline $\begin{array}{l}\text { Pengadaan listrik } \\
\text { dan gas (PLG) }\end{array}$ & $\beta_{3}$ & 60,540 & 3,565 & 0,000 \\
\hline Konstruksi (KTK) & $\beta_{5}$ & 3,381 & 5,260 & $\begin{array}{r}1,345 \mathrm{e}- \\
06\end{array}$ \\
\hline $\begin{array}{l}\text { Transportasi dan } \\
\text { pergudangan (TP) }\end{array}$ & $\beta_{7}$ & 1,075 & 11,172 & $\begin{array}{r}<2,2 \mathrm{e}- \\
16\end{array}$ \\
\hline $\begin{array}{l}\text { Jasa Perusahaan } \\
\text { (JPRS) }\end{array}$ & $\beta_{12}$ & 4,764 & 0,529 & 0,598 \\
\hline \multirow[t]{4}{*}{$\begin{array}{l}\text { Jasa Pendidikan } \\
\text { (JP) }\end{array}$} & $\beta_{14}$ & $-0,523$ & $-0,60$ & 0,545 \\
\hline & & & $F_{\text {hit }}$ & 485,032 \\
\hline & & & $p_{\text {value }}$ & $\begin{array}{l}<2,22 \mathrm{e} \\
-16\end{array}$ \\
\hline & & & $R^{2}$ & $97,86 \%$ \\
\hline
\end{tabular}

Sumber: Data diolah, 2020

Tabel 3. Parameter Model Fixed Time Effect

\begin{tabular}{|c|c|c|c|c|}
\hline Variabel & $\begin{array}{l}\text { Para } \\
\text { meter }\end{array}$ & $\begin{array}{l}\text { Nilai } \\
\text { Estimasi }\end{array}$ & $t_{\text {hit }}$ & $p$-Value \\
\hline 2010 & $\alpha_{1}$ & $-1436,73$ & $-2,63 t$ & 0,010 \\
\hline 2011 & $\alpha_{2}$ & $-989,50$ & $-1,85 \varepsilon$ & 0,067 \\
\hline 2012 & $\alpha_{3}$ & $-1258,47$ & $-2,39$ & 0,019 \\
\hline 2013 & $\alpha_{4}$ & $-2325,32$ & $-4,26 t$ & $\begin{array}{l}5.876 \mathrm{e}- \\
05\end{array}$ \\
\hline 2014 & $\alpha_{5}$ & $-855,81$ & $-1,48$ & 0,142 \\
\hline 2015 & $\alpha_{6}$ & $-1608,72$ & $-2,44$ & 0,017 \\
\hline 2016 & $\alpha_{7}$ & $-2231,19$ & $-3,07$ & 0,002 \\
\hline 2017 & $\alpha_{8}$ & $-2553,53$ & $-3,26 i$ & 0,001 \\
\hline 2018 & $\alpha_{9}$ & $-2451,11$ & $-3,03 ;$ & 0,003 \\
\hline 2019 & $\alpha_{10}$ & $-2602,01$ & $-3,16 i$ & 0,002 \\
\hline $\begin{array}{l}\text { Pertanian, } \\
\text { kehutanan, dan } \\
\text { perikanan }(\mathrm{PKP})\end{array}$ & $\beta_{1}$ & 2,319 & 11,804 & $\begin{array}{l}<2,2 \mathrm{e}- \\
16\end{array}$ \\
\hline $\begin{array}{l}\text { Industri } \\
\text { pengolahan (IP) }\end{array}$ & $\beta_{2}$ & 2,472 & 4,303 & $\begin{array}{l}5,145 \mathrm{e}- \\
05\end{array}$ \\
\hline $\begin{array}{l}\text { Pengadaan listrik } \\
\text { dan gas (PLG) }\end{array}$ & $\beta_{3}$ & 74,469 & 5,056 & $\begin{array}{l}3,071 \mathrm{e}- \\
06\end{array}$ \\
\hline Konstruksi (KTK) & $\beta_{5}$ & 3,724 & 7,578 & $\begin{array}{l}8,691 \mathrm{e}- \\
11\end{array}$ \\
\hline $\begin{array}{l}\text { Transportasi dan } \\
\text { pergudangan (TP) }\end{array}$ & $\beta_{7}$ & 1,357 & 17,233 & $\begin{array}{l}<2,2 \mathrm{e}- \\
16\end{array}$ \\
\hline $\begin{array}{l}\text { Jasa Perusahaan } \\
\text { (JPRS) }\end{array}$ & $\beta_{12}$ & $-0,129$ & $-0,03$; & 0,970 \\
\hline \multirow[t]{4}{*}{$\begin{array}{l}\text { Jasa Pendidikan } \\
(\mathrm{JP})\end{array}$} & $\beta_{14}$ & $-0,386$ & $-0,74 !$ & 0,458 \\
\hline & & & $F_{\text {hit }}$ & 1275,36 \\
\hline & & & $p_{\text {value }}$ & $\begin{array}{l}<2,22 \mathrm{e}- \\
16\end{array}$ \\
\hline & & & $R^{2}$ & $99,18 \%$ \\
\hline
\end{tabular}

Sumber: Data diolah, 2020

\subsection{Model Random Effect}

Nilai estimasi model random effect ditunjukkan pada Tabel 4.

Tabel 4. Parameter Model Random Effect

\begin{tabular}{|c|c|c|c|c|}
\hline Variabel & $\begin{array}{l}\text { Para } \\
\text { mete } \\
\mathrm{r}\end{array}$ & $\begin{array}{l}\text { Nilai } \\
\text { Estimasi }\end{array}$ & $t_{\text {hit }}$ & $p$-Value \\
\hline Intersep & $\alpha$ & $-723,509$ & $-1,32 \varepsilon$ & 0,184 \\
\hline $\begin{array}{l}\text { Pertanian, } \\
\text { kehutanan, dan } \\
\text { perikanan }(\mathrm{PKP})\end{array}$ & $\beta_{1}$ & 1,983 & 9,223 & $\begin{array}{l}<2,2 \mathrm{e}- \\
16\end{array}$ \\
\hline $\begin{array}{l}\text { Industri } \\
\text { pengolahan (IP) }\end{array}$ & $\beta_{2}$ & 2,127 & 2,502 & 0,012 \\
\hline $\begin{array}{l}\text { Pengadaan listrik } \\
\text { dan gas (PLG) }\end{array}$ & $\beta_{3}$ & 57,470 & 4,439 & $\begin{array}{l}9,035 \mathrm{e}- \\
06\end{array}$ \\
\hline Konstruksi (KTK) & $\beta_{5}$ & 3,949 & 7,030 & $\begin{array}{l}2,057 \mathrm{e}- \\
12\end{array}$ \\
\hline $\begin{array}{l}\text { Transportasi dan } \\
\text { pergudangan (TP) }\end{array}$ & $\beta_{7}$ & 1,157 & 12,961 & $\begin{array}{l}<2,2 \mathrm{e}- \\
16\end{array}$ \\
\hline $\begin{array}{l}\text { Jasa Perusahaan } \\
\text { (JPRS) }\end{array}$ & $\beta_{12}$ & 3,184 & 0,532 & 0,594 \\
\hline \multirow[t]{4}{*}{$\begin{array}{l}\text { Jasa Pendidikan } \\
\text { (JP) }\end{array}$} & $\beta_{14}$ & $-0,161$ & $-0,24 \mathrm{C}$ & 0,802 \\
\hline & & & $\boldsymbol{F}_{\text {hit }}$ & 4631,51 \\
\hline & & & $p_{\text {value }}$ & $\begin{array}{l}<2,22 \mathrm{e} \\
-16\end{array}$ \\
\hline & & & $R^{2}$ & $98,26 \%$ \\
\hline
\end{tabular}

Sumber: Data diolah, 2020

\subsection{Uji Chow dan Uji Hausman}

\section{Uji Chow}

Pada uji ini mempertimbangkan intersep, dengan hipotesis sebagai berikut:

$H_{0}: \alpha_{1}=\alpha_{2}=\alpha_{3}=\cdots=\alpha_{9}$

$H_{1}$ : ada satu $\alpha_{i} \neq \alpha_{j}$

Dari hasil perhitungan, memperoleh nilai $p_{\text {value }}=0,012<\alpha(0,05), \quad$ maka keputusannya tolak $H_{0}$. Hal ini berarti minimal terdapat satu kabupaten/kota yang memiliki perbedaan intersep. Sehingga model yang cocok yaitu model fixed time effect.

\section{Uji Hausman}

Uji ini akan membandingkan FEM dengan REM, dengan hipotesis sebagai berikut:

$H_{0}: E\left(w_{i t} \mid X_{i t}\right)=0$

$H_{1}: E\left(w_{i t} \mid X_{i t}\right) \neq 0$

Hasil perhitugan diperoleh, nilai $p_{\text {value }}=$ $0,000<\alpha(0,05)$. Maka tolak $H_{0}$, yang berarti bahwa model random effect tidak konsisten. Sehingga fixed time effect yang digunakan untuk analisis selanjutnya. 


\subsection{Uji Signifikan Parameter}

Terdiri atas dua tahap pengujian yaitu uji $\mathrm{F}$ (simultan) dan uji $\mathrm{T}$ (parsial). Pada uji $\mathrm{F}$ dengan memperhatikan model yang terpilih yaitu model fixed time effect dalam Tabel 3 . diperoleh nilai $p_{\text {value }}=<2,22 e-16<$ $\alpha(0,05)$, maka tolak $H_{0}$. Hal tersebut menunjukkan ada variabel bebas yang berpengaruh terhadap variabel respon.

Pada pengujian menggunakan uji t dengan model fixed time effect yang terdapat dalam Tabel 3. diperoleh bahwa pertanian, kehutanan, dan perikanan (PKP), industri pengolahan (IP), pengadaan listrik dan gas (PLG), konstruksi (KTK), serta transportasi, dan pergudangan (TP) memiliki nilai $p_{\text {value }}<\alpha(0,05)$, maka tolak $H_{0}$. Maka, kelima variabel tersebut berpengaruh signifikan terhadap PDRB Provinsi Bali.

\subsection{Uji Kebergantungan Spasial}

Terdapat dua uji yang dilakukan uji pengaruh lag spasial dan uji pengaruh error spasial yang dilakukan dengan menggunakan Lagrange Multiplier (LM). Secara singkat perolehan hasil ditunjukkan pada Tabel 5.

Tabel 5. Hasil Uji Lagrange Multiplier

\begin{tabular}{lcc}
\hline Model & $\begin{array}{l}\text { Statistik Uji } \\
\text { LM }\end{array}$ & $\begin{array}{l}\boldsymbol{p} \text { - } \\
\text { Value }\end{array}$ \\
\hline $\begin{array}{l}\text { Spatial lag model } \\
\text { (SAR) }\end{array}$ & 0,0081 & 0,0019 \\
\hline $\begin{array}{l}\text { Spatial error model } \\
\text { (SEM) }\end{array}$ & 3,8681 & 0,63 \\
\hline
\end{tabular}

Sumber: Data diolah, 2020

Pada tabel di atas diperoleh model spatial lag memiliki $p_{\text {value }}<\alpha(0,05)$, maka keputusannya tolak $H_{0}$. Dengan demikian, terdapat kebergantungan spasial terhadap variabel respon.

\subsection{Model Spatial Lag Fixed Effect}

Nilai estimasi model random effect ditunjukkan pada Tabel 6.
Tabel 6. Parameter Model Spatial Lag Fixed Effect

\begin{tabular}{|c|c|c|c|c|}
\hline Variabel & $\begin{array}{l}\text { Para } \\
\text { meter }\end{array}$ & $\begin{array}{l}\text { Nilai } \\
\text { Estimasi }\end{array}$ & Wald & $\boldsymbol{p}$-Value \\
\hline Intersep & $\hat{\beta}_{0}$ & 22,28 & 0,053 & 0,957 \\
\hline $\begin{array}{l}\text { Pertanian, } \\
\text { kehutanan, dan } \\
\text { perikanan (PKP) }\end{array}$ & $\hat{\beta}_{1}$ & 2,2478 & 13,362 & $<2,2 \mathrm{e}-16$ \\
\hline $\begin{array}{l}\text { Industri } \\
\text { pengolahan (IP) }\end{array}$ & $\hat{\beta}_{2}$ & 1,9470 & 3,779 & 0,0001 \\
\hline $\begin{array}{l}\text { Pengadaan listrik } \\
\text { dan gas (PLG) }\end{array}$ & $\hat{\beta}_{3}$ & 77,1702 & 6,161 & $7,213 \mathrm{e}-10$ \\
\hline Konstruksi (KTK) & $\hat{\beta}_{5}$ & 4,4152 & 9,432 & $<2,2 \mathrm{e}-16$ \\
\hline $\begin{array}{l}\text { Transportasi dan } \\
\text { pergudangan }(\mathrm{TP})\end{array}$ & $\hat{\beta}_{7}$ & 1,2156 & 15,281 & $<2,2 \mathrm{e}-16$ \\
\hline $\begin{array}{l}\text { Jasa Perusahaan } \\
\text { (JPRS) }\end{array}$ & $\hat{\beta}_{12}$ & 3,3291 & 1,060 & 0,2888 \\
\hline $\begin{array}{l}\text { Jasa Pendidikan } \\
\text { (JP) }\end{array}$ & $\hat{\beta}_{14}$ & $-0,8815$ & $-1,895$ & 0,0580 \\
\hline $\begin{array}{l}\text { Autokorelasi } \\
\text { Spasial }\end{array}$ & $\hat{\delta}$ & $-0,1160$ & $-3,338$ & 0,0008 \\
\hline
\end{tabular}

Sumber: Data diolah, 2020

Dari hasil $p_{\text {value }} \hat{\delta}$ lebih kecil dari pada $\alpha(0,05)$. Hal tersebut, terdapat kebergantungan lag terhadap variabel respon. Memiliki variabel bebas yang signifikan yaitu pertanian, kehutanan, dan perikanan (PKP), industri pengolahan (IP), pengadaan, listrik, dan gas (PLG), konstruksi (KTK), serta transportasi, dan pergudangan (TP) dengan $p_{\text {value }}<$ $\alpha(0,05)$.

\subsection{Interpretasi Model}

Model yang terbentuk pada spatial lag fixed effect sebagai berikut:

$$
\begin{aligned}
& Y_{i t}=22,28-0,116 \sum_{j=1}^{9} w_{i j} Y_{j t}+2,247 P K P_{i t} \\
& +1,947 I P_{i t}+77,170 P L G_{i t}+4,415 K T K_{i t} \\
& +1,215 T P_{i t}+3,329 J P R S_{i t}-0,881 J P_{i t} \\
& +\mu_{t}+\varepsilon_{i t} ; i, j=1,2, \cdots 9 \\
& ; i \neq j ; t=2010, \cdots 2019
\end{aligned}
$$

Model spatial lag fixed effect diatas memiliki perbedaan nilai konstanta di setiap waktu, karena terdapat effect time series. Nilai pengaruh waktu dapat dilihat dalam Tabel 7. 
Tabel 7. Dugaan Pengaruh Waktu

\begin{tabular}{cc}
\hline Tahun & Pengaruh \\
\hline 2010 & -437.217 \\
\hline 2011 & 129.321 \\
\hline 2012 & -104.781 \\
\hline 2013 & -788.504 \\
\hline 2014 & 895.145 \\
\hline 2015 & 371.257 \\
\hline 2016 & -71.199 \\
\hline 2017 & -233.860 \\
\hline 2018 & 102.193 \\
\hline 2019 & 137.643 \\
\hline
\end{tabular}

Sumber: Data diolah, 2020

Persamaan model spatial lag fixed effect yang berpengaruh signifikan dapat diinterpretasikan sebagai berikut:

1. Pada tahun amatan ke- $t$, koefisien $\delta=-0,116$ bermakna jika nilai PDRB suatu wilayah ke- $i$ akan berkurang sebesar 0,116 kali dari rataan nilai PDRB wilayah yang bertetanggaan terhadap wilayah tersebut.

2. Pada tahun amatan ke- $t$, koefisien $\beta_{1}=2,247$ bermakna ketika pertanian, kehutanan dan perikanan pada suatu kabupaten/kota $\mathrm{ke}-i$ meningkat sebesar 1\% dibandingkan kabupaten lainnya maka PDRB kabupaten/kota tersebut akan meningkat sebesar 2,247 miliar pada tahun tersebut, dengan asumsi variabel lainnya bernilai tetap dan sama dengan kabupaten/kota lainnya.

3. Pada tahun amatan ke- $t$, koefisien $\beta_{2}=1,947$ bermakna ketika industri pengolahan pada suatu kabupaten/kota ke $-i$ meningkat sebesar 1\% dibandingkan kabupaten lainnya maka PDRB kabupaten/kota tersebut akan meningkat sebesar 1,947 miliar pada tahun tersebut, dengan asumsi variabel lainnya bernilai tetap dan sama dengan kabupaten/kota lainnya.

4. Pada tahun amatan ke- $t$, koefisien $\beta_{3}=77,170$ bermakna ketika pengadaan listrik dan gas pada suatu kabupaten/kota ke $-i$ meningkat sebesar 1\% dibandingkan kabupaten lainnya maka PDRB kabupaten/kota tersebut akan meningkat sebesar 77,170 miliar pada tahun tersebut, dengan asumsi variabel lainnya bernilai tetap dan sama dengan kabupaten/kota lainnya.
5. Pada tahun amatan ke- $t$, koefisien $\beta_{5}=4,415$ bermakna ketika konstruksi pada suatu kabupaten/kota $\mathrm{ke}-i$ meningkat sebesar $1 \%$ dibandingkan kabupaten lainnya maka PDRB kabupaten/kota tersebut akan meningkat sebesar 4,415 miliar pada tahun tersebut, dengan asumsi variabel lainnya bernilai tetap dan sama dengan kabupaten/kota lainnya.

6. Pada tahun amatan ke- $t$, koefisien $\beta_{7}=1,215$ bermakna ketika transportasi dan pergudangan pada suatu kabupaten/kota ke- $i$ meningkat sebesar 1\% dibandingkan kabupaten lainnya maka PDRB kabupaten/kota tersebut akan meningkat sebesar 1,215 miliar pada tahun tersebut, dengan asumsi variabel lainnya bernilai tetap dan sama dengan kabupaten/kota lainnya.

\section{KESIMPULAN DAN SARAN}

\subsection{Kesimpulan}

Model terbaik pada penelitian ini yaitu model spatial lag fixed effect dengan $R^{2}$ sebesar 99,41\%, hal tersebut menunjukkan variabel bebas pada model dapat menjelaskan PDRB Provinsi Bali 99,41\%, sedangkan sisanya dijelaskan oleh variabel lain yang tidak diteliti.

Diperoleh variabel bebas yang signifikan mempengaruhi produk domestik regional bruto di Provinsi Bali adalah pertanian kehutanan dan perikanan, industri pengolahan, pengadaan gas dan listrik, konstruksi, serta transportasi dan, pergudangan.

\subsection{Saran}

Diharapkan untuk lebih memperhatikan sektor-sektor seperti pengadaan listrik dan gas, konstruksi, pertanian kehutanan dan perikanan yang berpengaruh terhadap PDRB Bali, maka dapat dijadikan patokan dalam pengembangan pertumbuhan ekonomi agar tidak mengandalkan bidang pariwisata.

\section{DAFTAR PUSTAKA}

Baltagi, B. H., 2005. Econometric Analysis of Panel Data. 3rd. England: John Wiley \& Sons Ltd. 
Bank Indonesia, 2019. Produk Domestik Regional Bruto (PDRB). Jakarta: Bank Indonesia.

BPS Bali, 2019. Produk Domestik Regional Bruto Provinsi Bali Menurut Lapangan Usaha 2014-2018. Bali: Badan Pusat Statistik Provinsi Bali.

BPS Provinsi Bali, 2019. Pertumbuhan Ekonomi Bali Tahun 2019. Bali: Badan Pusat Statistik Provinsi Bali.

Gujarati, D. N. \& Porter, D. C., 2009. Basic Econometrics. 5th. New York: The McGraw-Hill.

Haryanto, S. \& Saryono, A., 2018. Pemodelan PDRB Sektor Kontruksi di Jawa Timur Tahun 2010-2015 dengan Regresi Data
Panel. Jurnal MSA, Volume 06, No. 2, pp. 1-7.

Lasdiyanti, M., Kencana, E. N. \& Suciptawati, P., 2019. Modeling Human Development Index of Bali with Spatial Panel Data Regression. European Journal of Engineering Research And Science, Volume 4, No. 5, pp. 1-5.

LeSage, J. P., 1999. The Theory and Practice of Spatial Econometrics. United States: University of Toled.

Widiadnyani, N. L. G., Suciptawati \& Susilawati, 2019. Model angka partisipasi sekolah jenjang SMA sederajat di Provinsi Bali. E-Jurnal Matematika, Volume 8(3), pp. 179-183. 